\title{
Cardiac Mucormycosis Presenting as a "Fungus Ball" in the Left Atrium
}

\author{
Katsuya Chinen, Hirofumi Matsumoto and Yasunori Fujioka
}

Key words: heart, mucormycosis, fungus ball

(Inter Med 48: 1781-1782, 2009)

(DOI: 10.2169/internalmedicine.48.2611)

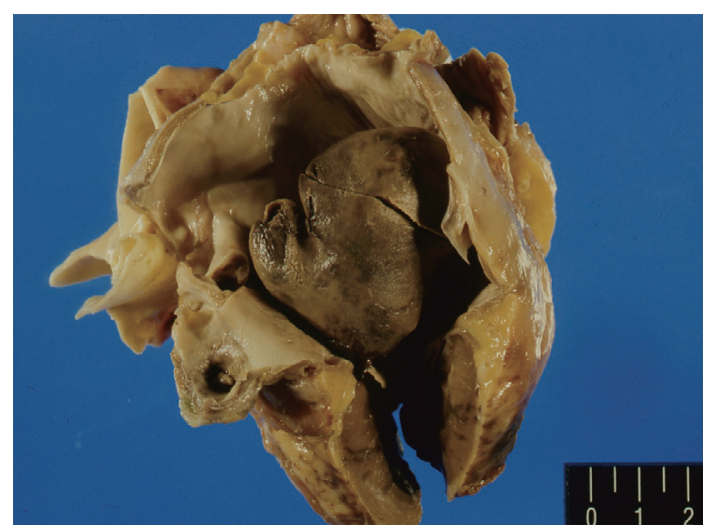

Picture 1. A large thrombus-like mass measuring $5 \times 5 \times 4$ cm occupied the left atrial cavity.

A 71-year-old woman with myelodysplastic syndrome was admitted because of fever and treated with antibacterial agents. On the second hospital day, she presented with dysarthria and right arm paresis and was diagnosed as cerebral infarction. On the fourth hospital day, she suddenly died. An autopsy revealed a left atrial mass caused by mucormycosis (Pictures 1, 2). Systemic fungal embolism, including the brain, was also pathologically confirmed.

Cardiac fungal infection (CFI) is increasing and the incidence of Mucor or Aspergillus species as a causative pathogen is on the rise (1). Although antemortem diagnosis of

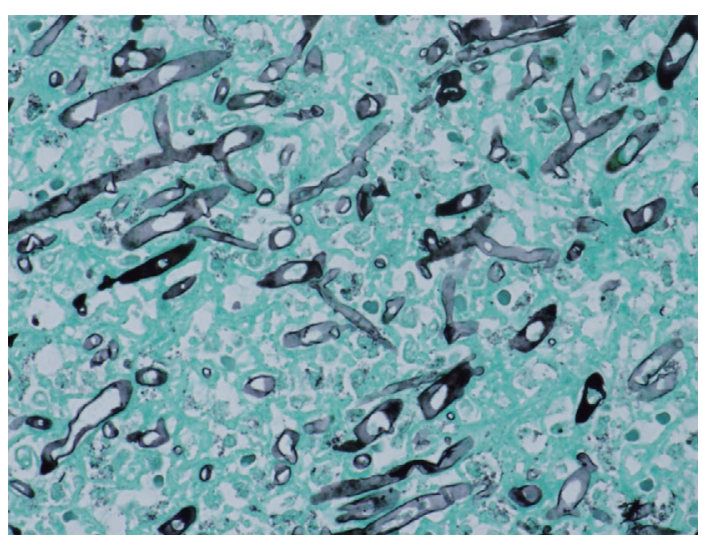

Picture 2. Histologically, the cardiac mass consisted of fungal elements enmeshed with fibrinous material. The fungus showed the characteristic morphology of Mucor species featuring large nonseptate hyphae with right-angle branching (methenamine silver stain).

CFI remains rare and difficult, early diagnosis can be made by histopathological methods with a cardiac mass or peripheral embolus (2-4). In patients with suspected CFI, cardiac mass formation or peripheral embolism should be considered as a possibility for early diagnosis, because CFI is potentially treatable (1-4), even in cases of disseminated mucormycosis (5).

\section{References}

1. Chinen K, Tokuda Y, Sakamoto A, Fujioka Y. Fungal infections of the heart: a clinicopathologic study of 50 autopsy cases. Pathol Res Pract 203: 705-715, 2007.

2. Vida V, Biffanti R, Thiene G, Stellin G, Milanesi O, Basso C. Images in cardiovascular medicine. Left ventricular mass after treatment with chemotherapic drugs. Circulation 109: e300-e301,
2004.

3. Sanchez-Recalde A, Merino JL, Dominguez F, Mate I, Larrea JL, Sabrino JA. Successful treatment of prosthetic aortic valve mucormycosis. Chest 116: 1818-1820, 1999.

4. Chaudhry R, Venugopal P, Chopra P. Prosthetic mitral valve mucormycosis caused by Mucor species. Int J Cardiol 17: 333-335, 
Inter Med 48: 1781-1782, 2009 DOI: 10.2169/internalmedicine.48.2611

1987.

5. Gonzalez CE, Couriel DR, Walsh TJ. Disseminated zygomycosis in a neutropenic patient: successful treatment with amphotericin B lipid complex and granulocyte colony-stimulating factor. Clin Infect Dis 24: 192-196, 1997.

(C) 2009 The Japanese Society of Internal Medicine http://www.naika.or.jp/imindex.html 